\title{
REVIEW
}

\section{The secret service - analysis of the available knowledge on moths as pollinators in New Zealand}

\section{Te pepe huna - he tātarihaka o te mātauraka rakahau ki kā pepe hai whakaaiai ki Aotearoa me Te Waipounamu}

\author{
Max N. Buxton ${ }^{1,3^{*}}$, Barbara J. Anderson ${ }^{2}$ and Janice M. Lord ${ }^{1}$ \\ ${ }^{1}$ Department of Botany, University of Otago, PO Box 56, Dunedin, New Zealand \\ ${ }^{2}$ Landcare Research, Private Bag 1930, Dunedin, New Zealand \\ ${ }^{3}$ The New Zealand Institute for Plant \& Food Research Limited, Ruakura Research Centre, Hamilton 3240, New Zealand \\ *Author for correspondence (Email: max.buxton@plantandfood.co.nz)
}

Published online: 14 December 2017

\begin{abstract}
On a global-scale, moths (Lepidoptera) are considered to be important pollinators for many plant families. However, the assumption that moths are also involved in pollination in New Zealand is underpinned by relatively little research. Here we review the evidence for moth pollination of flowering plants in New Zealand and compare the quality of evidence available with that of the global literature. Globally, the majority of experimental studies have focused on the hawkmoths (Sphingidae) and other specialist pollinators, leaving a substantial gap in knowledge concerning the role of smaller and more generalist moths as pollinators. New Zealand lacks native Sphingidae; however, members of Geometridae, Noctuidae and Erebidae, all identified as pollinators globally, are mentioned as flower-visitors in New Zealand more than expected given their family sizes. In addition to these families, Oecophoridae are mentioned as flower-visitors in New Zealand but this has not been documented globally, suggesting new mutualisms may have evolved in New Zealand. Eight plant families: Alseuosmiaceae, Argophyllaceae, Campanulaceae, Gentianaceae, Goodeniaceae, Montiaceae, Pittosporaceae and Stylidiaceae, were mentioned in the context of moth pollination in New Zealand, but not in the global literature. The Orchidaceae family is most frequently mentioned in the context of moth pollination globally, but was not mentioned at all in the New Zealand literature, despite two endemic genera, Winika and Earina, showing floral features suggestive of moth pollination. The evidence to support pollination by moths in New Zealand comes predominantly from observations of flower-visitation and assumptions based on floral features. As this is not proof of effective pollen transfer, detailed experimental studies are required before the importance of moths as pollinators in New Zealand can be accurately gauged.
\end{abstract}

Tuhika Whakarāpopoto: Ki te ao whānui, he whakaaiai whakahirahira kā pepe (Lepidoptera) ki kā tipu whaipua. Heoi, he iti noa te puna rakahau hai taunaki i te whakatatau he orite te mahi a kā pepe i Aotearoa me Te Waipounamu ('Aotearoa'). Ka tātari mātou i te rakahau e hākai ana ki te whakaaiai ā-pepe i kā tipu whaipua i Aotearoa, $\bar{a}, k a$ whakatairite i te pai o te puna rakahau ki Aotearoa nei ki tō te ao. Ka arotahi te nuika o kā tuhika rakahau ā-ao ki kā ko Pepe Hīhue (Sphingidae) me ētahi atu pepe whakaaiai tauwhāiti. Kāore kā tuhika à-ao e tirohia whānuitia te mahi a kā pepe iti iho me kā pepe mahi tauwhānui hai whakaaiai. Kāore he Sphingidae taketake ki Aotearoa, ekari ko ētahi pepe ko Pepe Tāwhana (Geometridae), ko Pepe Whānui (Noctuidae) ko Pepe Mokarakara (Erebidae) hoki, e mōhiotia ana he whakaaiai i kā tuhika ā-ao, ka meatia ki kā tuhika $\bar{a}$-Aotearoa he kaitoro-pua i kā wā maha, ahakoa te iti o ō rātou momo. I kitea hoki kā pepe Oecophoridae e toro-pua ana i kā tuhika ā-Aotearoa, kāore i kitea i kā tuhika ā-ao: he tohu pea ko panoni ētahi whakahoahoa hou ki Aotearoa. E waru kā momo tipu: Alseuosmiaceae, Argophyllaceae, Campanulaceae, Gentianaceae, Goodeniaceae, Montiaceae, Pittosporaceae me Stylidiaceae, i kitea i kā tuhika ā-Aotearoa e pā ana ki te whakaaiai ā-pepe, kāore i kitea i kā tuhika ā-ao. Ko pūputu rawa kā Orchidaceae i kā tuhika ā-ao e hākai ana ki te whakaaiai ā-pepe. Kāore kau i kitea taua momo pepe i kitea i kā tuhika ā-Aotearoa, ahakoa he momo tipu whaipua taketake ki konei, Winika me Earina, e whai āhuataka pua e hākai ana ki te whakaaiai ā-pepe. Ko te nuika o kā taunakitaka e tautoko ana i te whakaaiai ā-pepe i Aotearoa nei, he tirohaka ki te toro-pua me kā āhuataka pua. Ehara aua mea i kā tohu o te whakawhiti hae, nā reira me āta whakamātau kia mōhio ai te hira o kā pepe i Aotearoa hai whakaaiai.

Key words: Asteraceae; Ericaceae; experimentation; Geometridae; global patterns; Lepidoptera; mutualisms; Noctuidae; Oecophoridae; pollination 


\section{Introduction}

Globally, moths (Lepidoptera) are considered to be important pollinators for many plant families (MacGregor et al. 2014), with some of the most specialised pollination mutualisms known involving moths, e.g. yucca moths (Lepidoptera: Prodoxidae) and yucca plants (Asparagaceae: Agavoideae) (Morris et al. 2010; Yoder et al. 2010; Althoff 2016). However, compared with research into birds and diurnal insects, the role of moths as pollinators has been overlooked on a global scale (MacGregor et al. 2014).

Most moths, like butterflies, have a long thin proboscis enabling nectar feeding, although some families are nonfeeding as adults, and others such as the mandibulate Micropterygidae eat pollen (Faegri \& van der Pijl 1979). As adult moths are only feeding for themselves, and food intake is sometimes minimal, moths are generally regarded as unreliable pollinators (Faegri \& van der Pijl 1979), apart from a few families such as the Sphingidae hawkmoths (Johnson \& Raguso 2016). Nevertheless, moths may play an important role as pollinators for flowers that exhibit long, narrow, corolla tubes that short-tongued insect visitors cannot access (Darwin 1862; Benning 2015; Johnson \& Raguso 2016). The combination of nocturnal activity in most moth species, and the ability to access nectar in narrow corolla tubes, has led to the definition of a 'moth pollination' syndrome involving plants with pale, tubular flowers with nectar rewards that are strongly scented at night (Faegri \& van der Pjl 1979; Proctor et al. 1996). However, floral traits of species rarely conform to idealised pollination syndromes (Ollerton et al. 2009), and flowers visited by moths may also be visited and effectively pollinated by other functional groups (Spears 1983; King et al. 2013; Rosas-Guerrero et al. 2014), sometimes increasing the overall fitness of the plant (Johnson \& Steiner 2000).

Moths have diversified greatly in New Zealand, with possibly more than 2000 species, of which $92 \%$ are endemic (Patrick 2007). This diversification, combined with the fact that the New Zealand flora has an unusually high proportion of plant species with small, pale-coloured flowers (Godley 1979; Lloyd 1985; Campbell et al. 2010), has led to the longheld assumption that moth pollination might be particularly important in New Zealand (e.g. Thomson 1881, 1928; Heine 1937; Burrows 1960; Primack 1978, 1983; Godley 1979; Lloyd 1985; Robertson 1989; Newstrom \& Robertson 2005; Merrett et al. 2007; Pattemore \& Wilcove 2012; Pattemore \& Anderson 2013; Gardner-Gee et al. 2014). However, there are little quantitative data to support this assumption. For example, Primack (1983) is often cited as providing experimental evidence of pollination interactions in New Zealand, but he made no attempt to determine whether the insects observed were actually carrying pollen on their body. Owing largely to observational studies of floral visitation such as those of Primack (1979, 1983), New Zealand's pollination systems have been characterised as highly generalised with extensive pollinator sharing, and unpredictable and imprecise pollinator services (Thomson 1928; Primack 1978, 1983; Lloyd 1985; Newstrom $\&$ Robertson 2005; Ollerton et al. 2009). However, detailed experimental work has revealed discriminating foraging patterns by native insects, differences in effectiveness among insect taxa and thus more floral specialisation than previously thought (Bischoff 2008; Campbell et al. 2010; Bischoff et al. 2013; Miller et al. in review). Lloyd (1985) speculated that future studies may uncover more moth-pollinated plants in New Zealand, particularly in subalpine communities, but in the more than 30 years since this claim, there has been little attempt to further our understanding. Therefore, it is timely to ask whether assumptions about moth pollination in New Zealand are supported by evidence and what is the quality of the evidence, in order to identify gaps in our knowledge concerning the role of moths as pollinators.

This review will address four questions: (1) what is the strength of evidence for moth pollination in New Zealand? (2) How well represented in the New Zealand pollination literature are moth families indicated as pollinators elsewhere? (3) How well represented in New Zealand pollination literature are flowering plant families that elsewhere are thought to be pollinated by moths? (4) Are particular moth or plant families over- represented, relative to family size, in the New Zealand moth pollination literature?

\section{Materials and methods}

\section{Literature search}

An abstract, title and key word search in Web of Science Core Collection(v. 5.22) using 'moth', 'pollinat*' and 'New Zealand' as key words was conducted on 16 June 2015, and any paper that mentioned a moth-plant pollination interaction was included. This search was repeated on 16 December 2016 in an attempt to find any additional relevant literature; however, no further sources were identified. Published postgraduate student theses were included when a moth-plant pollination interaction was mentioned in New Zealand. New Zealand experts in the field were contacted for additional information, which was provided in the form of unpublished postgraduate student theses. In an attempt to put New Zealand's understanding of moth pollination in an Australasian context, an abstract, title and key word search in Web of Science Core Collection (v. 5.23) using 'moth', 'pollinat*' and 'Australia' as key words was conducted on 16 December 2016 to find any additional relevant literature, with three sources identified. It is acknowledged that even though the search of New Zealand literature was extensive, there may be additional sources that were not encountered. Global information was obtained from the supplementary material in MacGregor et al. (2014), and its use is solely intended to help explain and understand New Zealand current knowledge. Following MacGregor et al. (2014), from hereon for simplicity the terms 'pollination' and 'pollinator' are used when there is reasonable evidence that moths act as potential pollinators, even if this evidence is circumstantial, and even though in some instances the term 'visitor' may be more appropriate as pollination was not actually proven.

\section{The nature of evidence for moth pollination}

Evidence for moth pollination was categorised by both moth family and plant family into eight different evidence types (Table 1). These types of evidence were then ranked in order of the support they provided for moths as pollinators - with 'unknown' being the least conclusive and 'experimental' as the most conclusive evidence type. Many literature sources provided support for more than one moth and/or plant family, therefore the total number of mentions exceeded the number of publications. Species numbers for each plant family were obtained from the Angiosperm Phylogeny Group (Stevens 2001) and the New Zealand Indigenous Vascular Plant Checklist 2010 (de Lange \& Rolfe 2010). Global species number for each pollinating moth family were obtained from 
Table 1. Categories of evidence used to support moth pollination and description of what the evidence encompasses. Evidence is ranked in order, from least conclusive (unknown) to most conclusive (experimental).

\begin{tabular}{ll}
\hline Evidence & Description \\
\hline Unknown & It is unclear what evidence is available to support the claim. \\
Inferred & Pollination was inferred from floral syndromes. \\
Trace & The presence of moth scales or hairs on the stigma of flowers. \\
Visitation & Moths were observed visiting or foraging on the flower, or were caught on the flower. \\
Contact & Moths were observed making contact with the sex organs of the flower. \\
Pollen on moth bodies & Pollination is inferred from the presence of pollen on captured moth bodies. \\
Deposition & Pollen was observed to have been deposited on stigmas by moths. \\
Experimental & Effective pollination is shown by the use of pollinator exclusion experiments.
\end{tabular}

Van Niuekerken et al. (2011). Dr Robert Hoare (Landcare Research New Zealand Ltd.) provided the species numbers for each moth family in New Zealand.

\section{Data analysis}

Analyses were carried out at the family level for both moth and plant records, because a large proportion of information was restricted to this taxonomic level alone. Chi-squared tests were used to determine if families were mentioned more than expected based on family size, both in the New Zealand moth pollination literature and globally. To avoid expected family values of less than one, tests of the New Zealand data were restricted to families with more than 10 species. Data were collated and percentages calculated in Microsoft Excel. Chi-squared tests were conducted in Statistix V.9 (Analytical Software). All figures were constructed in R (version 3.2.1).

\section{Results}

\section{What is the evidence supporting moth pollination in New Zealand?}

There were more evidence types supporting moth pollination globally than in New Zealand (Fig. 1; Table 1). The two most conclusive evidence types, 'deposition' (pollen being deposited on stigma) and 'experimental' (e.g. exclusion of moths from
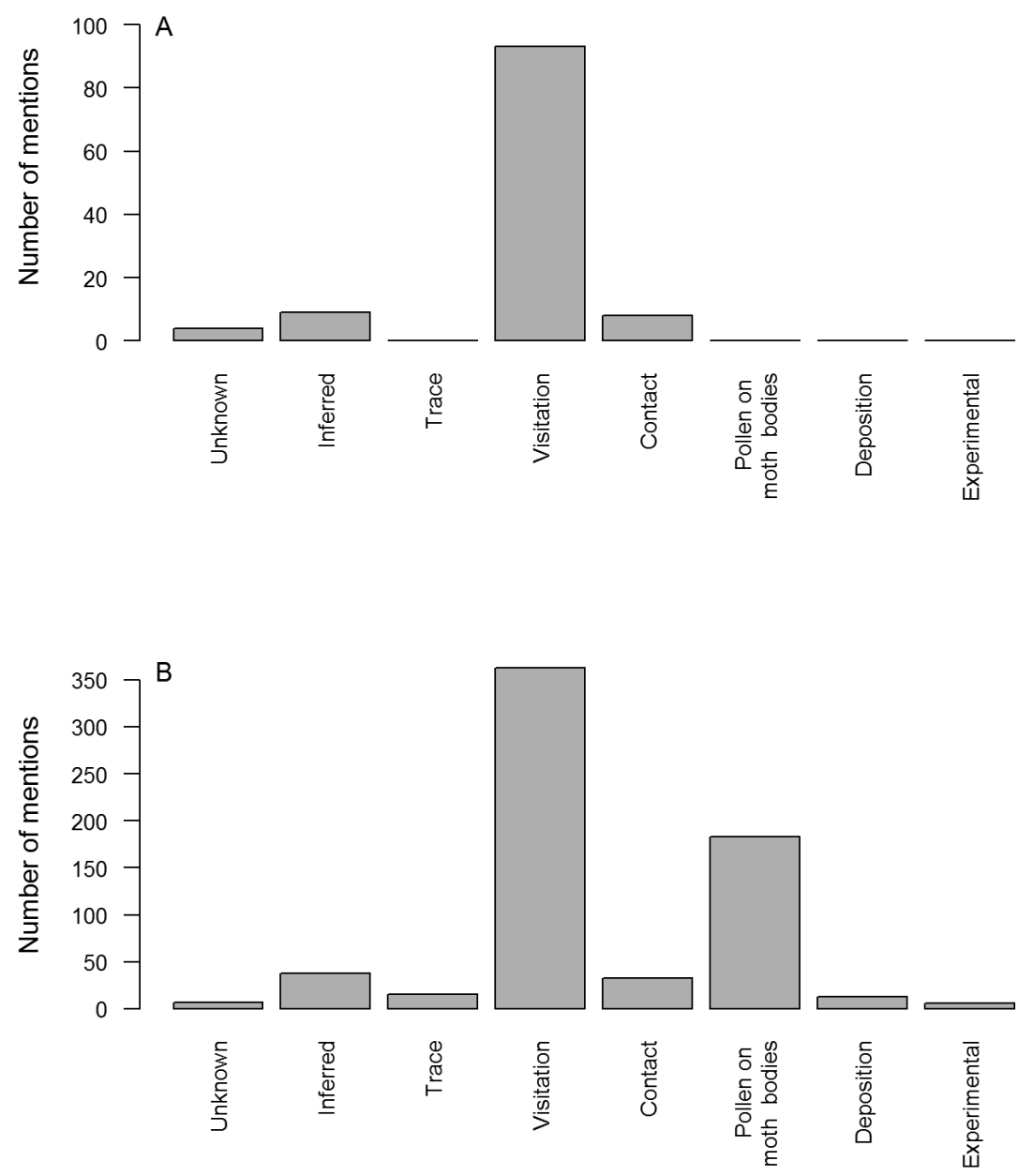

Figure 1. The number of times each type of evidence has been used in the scientific literature to support moth pollination in New Zealand (A) and globally (B). The inferential strength of the evidence is displayed in order of left to right, with the less conclusive evidence on the left (unknown) and the most conclusive evidence (experimental) on the right. 'Number of mentions' refers not to the number of papers that have made the suggestion, but to the number of times that a type of evidence has been used to support moth pollination. 
flowers) were not found in the New Zealand moth pollination literature (Fig. 1A). While pollination has been inferred from floral syndromes in New Zealand (7.8\% of mentions) as well as globally (5.6\% of mentions), visitation data are the most frequent evidence type to infer moth pollination (New Zealand: $80.9 \%$ of mentions; globally: $55.3 \%$ of mentions). The presence of pollen on moth bodies was mentioned only once in the New Zealand literature, but is the second-most mentioned evidence globally (Fig. 1). 'Trace' evidence is not mentioned in the New Zealand literature. Claims of moth pollination have arisen from 'unknown' evidence in New Zealand (3.5\% of mentions) and globally ( $1 \%$ of mentions). As these claims cannot be substantiated they could be discounted altogether.

\section{Moth families in the pollination literature in New Zealand and globally}

Ten moth families mentioned as including pollinators globally were not mentioned in the New Zealand literature, despite being present in New Zealand. Seven families (Crambidae, Geometridae, Noctuidae, Sphingidae, Pyralidae, Pterophoridae, Erebidae) identified globally as including pollinators were also mentioned in the New Zealand literature (Fig. 2A). In addition to these families, one cosmopolitan family Oecophoridae, which is abundant in New Zealand (151 species), was mentioned once in the New Zealand literature, but not globally in the context of pollination. These eight moth families are currently the only ones identified as involved in pollination in New Zealand. Geometridae species were identified most frequently as potential pollinators in New Zealand, followed closely by Noctuidae (Fig. 2A). Both of these families were also indicated as being important pollinators globally (Fig. 2B). Sphingidae and Pyralidae were mentioned regularly in the global literature yet are infrequently mentioned in the New Zealand literature (New Zealand has two and 24 species in these families, respectively). There were 70 mentions of moth pollination in the New Zealand literature where the identity of the moth was unknown, and these involve the largest variation in evidence types ('unknown', 'inferred' and 'contact' evidence; Fig. 2A). Geometridae was the only moth family in New Zealand with more than one type of evidence to support claims of pollination (visitation and pollen on moth bodies); the remaining families were all mentioned in the context of visitation data alone. In contrast, many families in the global literature were associated with a diversity of evidence types (Fig. 2B).

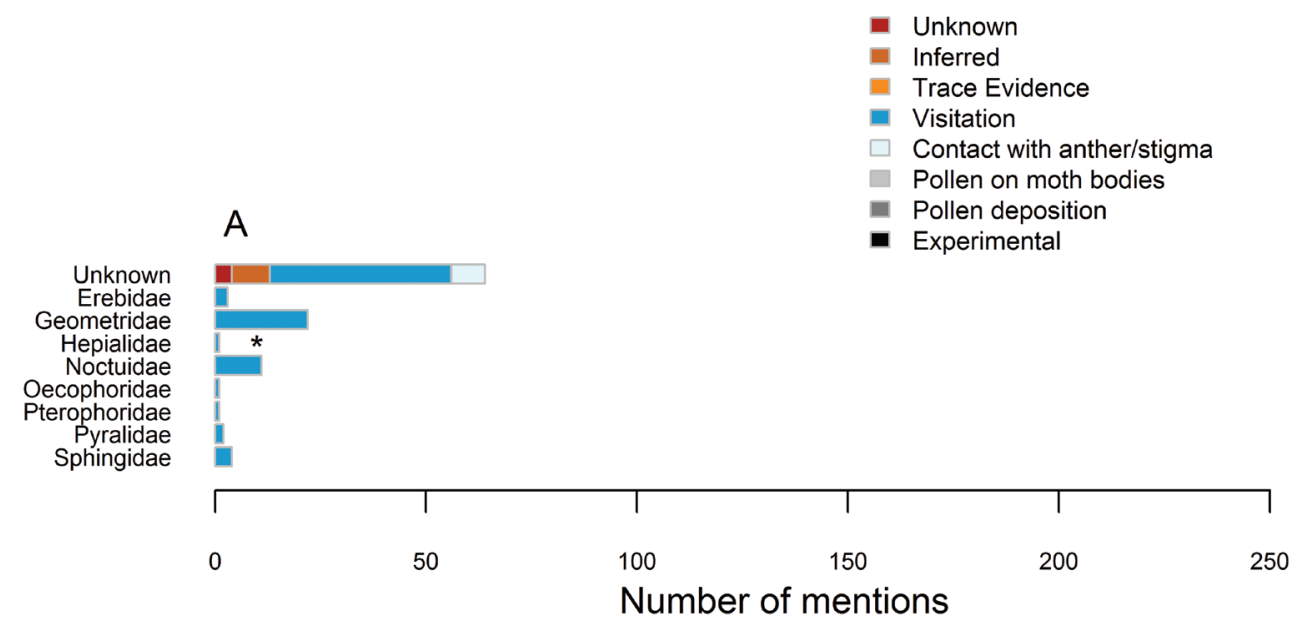

B

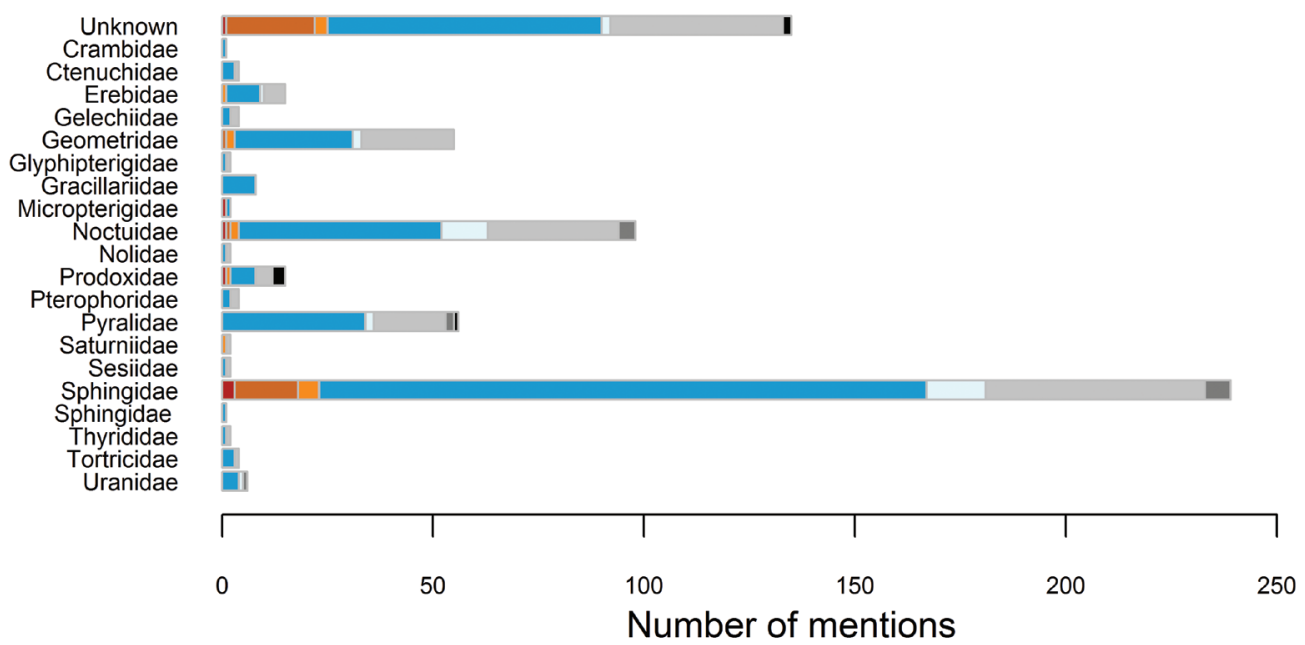

Figure 2. The different types of evidence used in scientific literature to support moth pollination for each moth family suggested as being a pollinator in New Zealand (A) and globally (B). 'Number of mentions' refers not to the number of papers that have made the suggestion, but to the number of times that a type of evidence has been used to support pollination by a particular moth. *Hepialidae is a family of non-feeding moths, however, Thomson (1928) reported that 'Colenso states that he thinks the moth Hepialus visits the flowers, which abound in honey' of Metrosideros robusta A. Cunn. Due to their non-feeding behaviour Hepialidae are not generally considered as potential pollinators; this record demonstrates the risks associated with a reliance on visitation data. 


\section{Over-representation of moth families in the pollination literature}

Larger moth families typically received more mentions in the pollination literature than smaller moth families (Fig. 3 ). However, the number of mentions departed significantly from expectations based on family size both in New Zealand $\left(\chi_{12}^{2}=40.35, \mathrm{P}<0.001\right)$ and globally $\left(\chi_{21}^{2}=7558.74, \mathrm{P}<\right.$ $0.001)$. Three families, Erebidae (23 species), Geometridae (278 species) and Noctuidae (151 species) were mentioned in New Zealand more often than expected given family size, and Tortricidae (151 species) was mentioned less often than expected (no mentions) (Fig. 3A). Globally, only Sphingidae, Nolidae, Prodoxidae and Pyralidae were mentioned more often than expected, with Sphingidae extremely over-represented in the global literature (Fig. 3B). New Zealand only has two non-native Sphingidae species, so it is not surprising that the family has only been mentioned twice (Fig. 3A). The Pyralidae and Erebidae families are similar in size in New Zealand, but Erebidae is four times more abundant than Pyralidae globally. However, Erebidae is mentioned significantly less often than expected globally (15 mentions) compared with 56 mentions globally of Pyralidae in association with pollination (Fig. 3B).

\section{Plant families in the moth pollination literature in New Zealand and globally}

Globally, 76 plant families have been mentioned in the context of moth pollination. Of these, 32 are not mentioned in the New Zealand moth pollination literature, despite being present in New Zealand. Thirty-one plant families in New Zealand have been mentioned in the context of moth pollination (Fig. 4A). Eight of these, Alseuosmiaceae, Argophyllaceae, Campanulaceae, Gentianaceae, Goodeniaceae, Montiaceae, Pittosporaceae and Stylidiaceae, have not been mentioned in the global literature on moth pollination. The five plant families that have received the most mentions in the New Zealand literature relating to moth pollination are Asteraceae, Ericaceae, Plantaginaceae, Myrtaceae and Campanulaceae, with the remaining families receiving five mentions or fewer.

\section{Over-representation of plant families in the moth pollination literature}

Larger plant families typically received more mentions in the moth pollination literature than smaller plant families (Fig. 4). However, the number of mentions departed significantly from expectations based on family size, both in New Zealand $\left(\chi_{29}^{2}=157.77, \mathrm{P}<0.001\right)$ and globally $\left(\chi_{62}^{2}=1949.71, \mathrm{P}\right.$ $<0.001)$. Four families were mentioned significantly more than expected in the New Zealand moth pollination literature: Campanulaceae (28 species, 10 mentions), Ericaceae (63 species, 16 mentions), Myrtaceae (24 species, 12 mentions) and Pittosporaceae (22 species, 6 mentions) (Fig. 4A). In contrast, these families were mentioned as often or less than expected in the global moth pollination literature. Asteraceae was the largest family mentioned with regard to moth pollination in New Zealand (449 species), but with just 13 mentions (Fig. 4A), it was under-represented, as was Orchidaceae (107 species, no mentions). In contrast, Orchidaceae was the most abundant (27 800 species) and most frequently mentioned
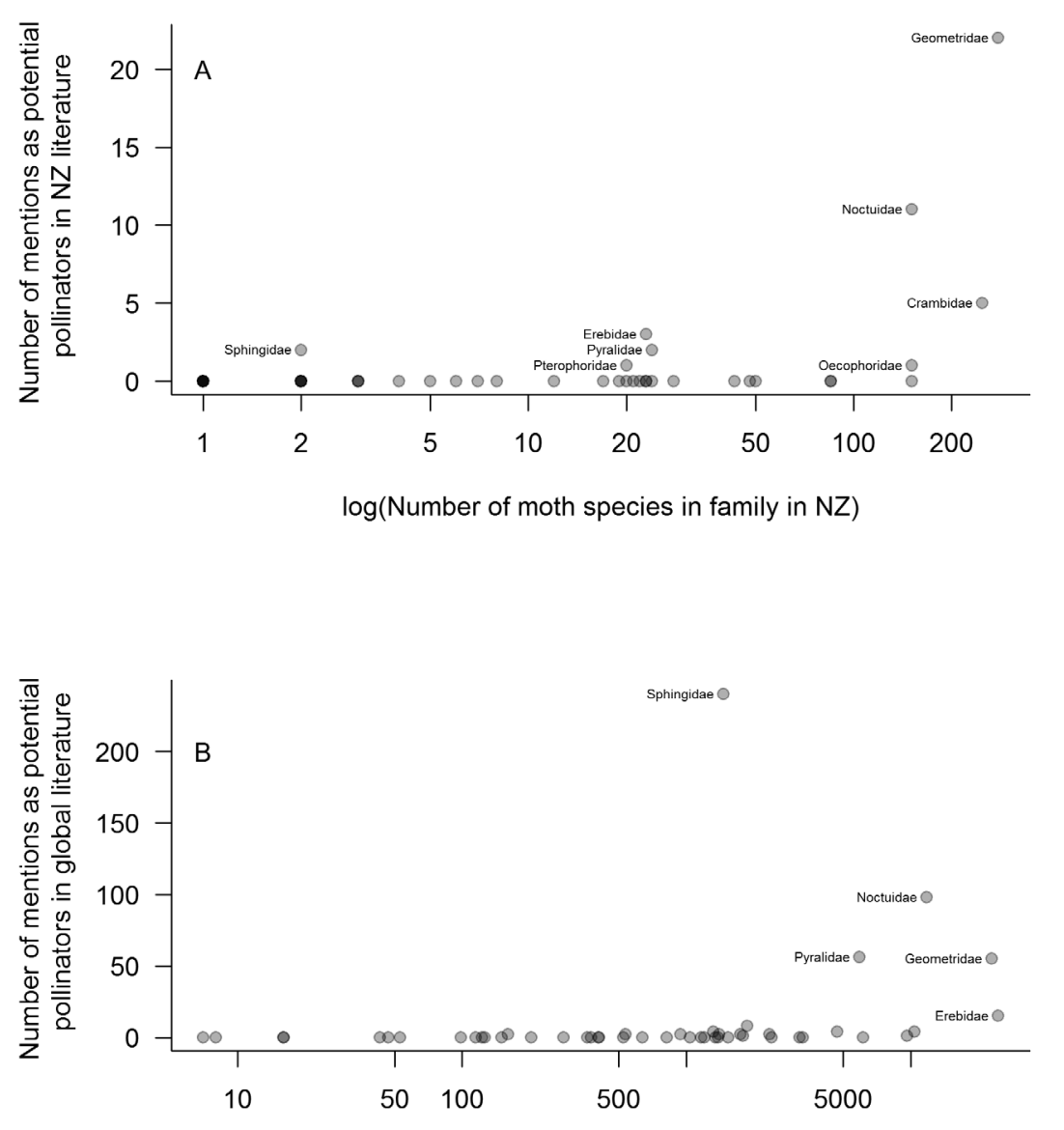

$\log$ (Number of species in family globally)
Figure 3. The relationship between moth family size $\left(\log ^{10}\right)$ and the number of times they have been suggested in scientific literature as being pollinators in New Zealand (A) and globally (B). Moth family names have been added for all moth families suggested as being pollinators more than once in New Zealand, while names have been added to moth families that have been suggested as being pollinators more than 10 times in the global literature. 

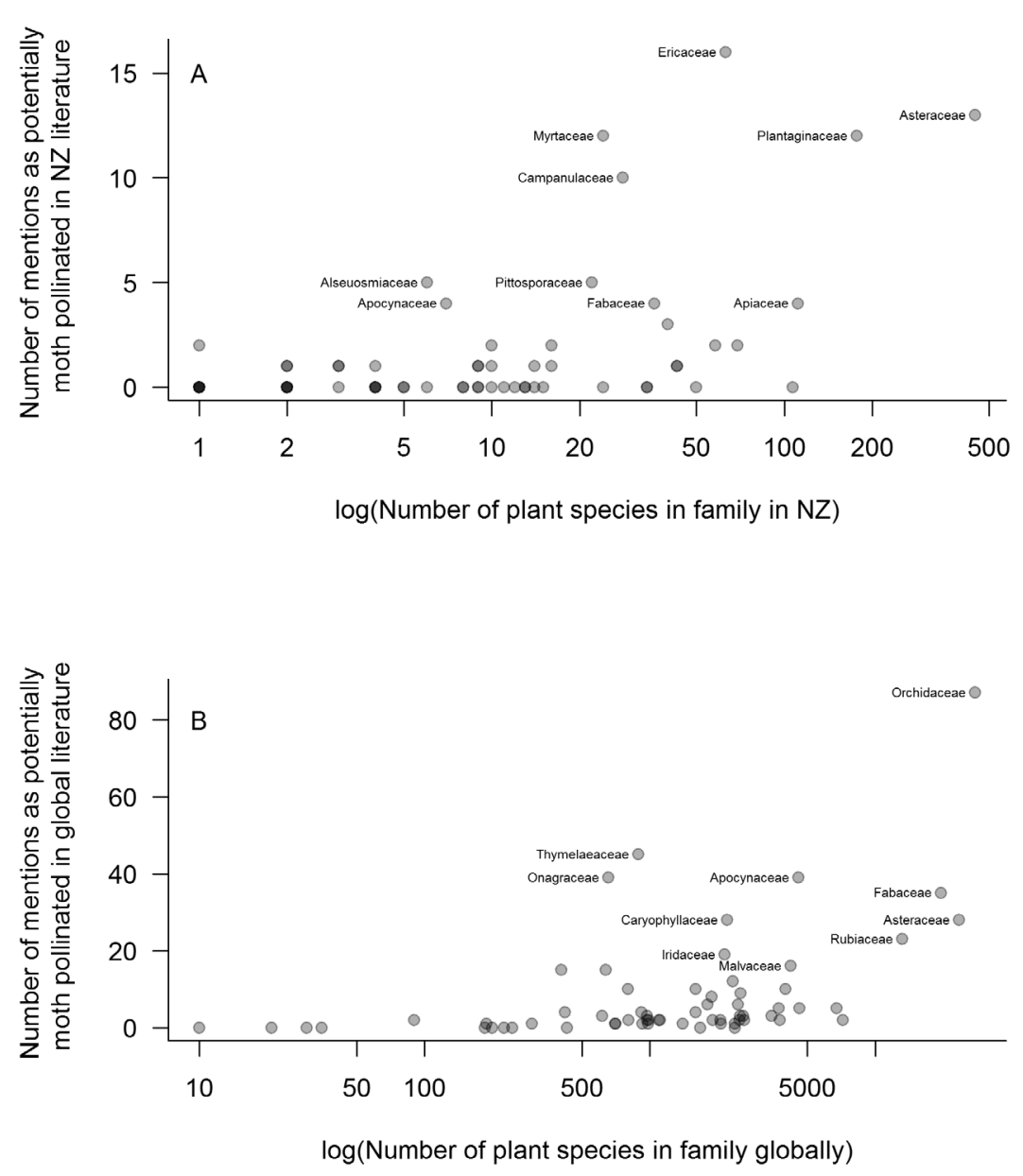

Figure 4. The relationship between plant family size $\left(\log ^{10}\right)$ and the number of times they have been suggested in scientific literature as being moth pollinated in New Zealand (A) and globally (B). For simplicity, plant family names are given for plant families that have been mentioned in New Zealand literature more than three times, and for plant families with more than 15 mentions in the global literature.
(87 mentions) plant family in the context of moth pollination globally (Fig. 4B). Of the families shared between the New Zealand and global datasets, Apocynaceae, Thymeleaceae, Iridaceae, Loganiaceae, Onagraceae and Winteraceae were all mentioned more than expected in the global literature, but received few if any mentions in the New Zealand literature (Fig. 4).

\section{Evidence for moth pollination in New Zealand versus Australia}

Only three sources were located in the Australian literature that offered support for moth pollination. The evidence types were generally strong, for example 'observations of pollination' (Keighery 1996), moths collecting pollen and depositing it upon pistillate flowers (van Welzen et al. 2015), and field observations, pollen on moth bodies, scales on stigmas and experimentation (Rodger et al. 2010). The plant families mentioned were Liliaceae, Phyllanthaceae and Epacridaceae.

\section{Discussion}

To be an effective pollinator, a visitor must remove and carry viable pollen and deposit it on a conspecific stigma when the stigma is receptive (King et al. 2013; Popic et al. 2013). However, the ability of an animal to act as a pollinator is often inferred from various indirect lines of evidence rather than proven, resulting in a range of evidence types offering different amounts of certainty. The stronger categories of evidence (e.g. pollen on moth bodies, pollen deposition on stigma, and experimental evidence) are more valuable as they allow for the effectiveness of a pollinator to be measured (Dieringer 1992).

\section{Evidence for moth pollination in New Zealand}

The role of moths as pollinators has been largely overlooked in New Zealand, and the evidence that is available is largely based upon observations of floral visitation, with the stronger evidence types available in the global literature being absent from the New Zealand literature. The dominance of quantitative data (e.g. numbers of floral visitors) is likely due to pollinator quantity being substantially easier to record in the field than pollinator quality (Fenster et al. 2004). However, moth visitation records in New Zealand are still low in comparison to other floral visitors, and this can be attributed to the difficulty associated with conducting surveys at night (Newstrom \& Robertson 2005; MacGregor et al. 2014). The New Zealand literature also contained reports of moths visibly contacting the reproductive organs of flowers. Whether these moths removed or deposited pollen after visiting flowers was not determined, so this evidence cannot be accepted as proof of pollination, as not all visitors to flowers act as pollinators (Genini et al. 2010; Hegland et al. 2010; King et al. 2013; Popic et al. 2013). Furthermore, visitation can be detrimental to a plant because the visitor can remove resources such as nectar and pollen that are better used by other more effective pollinators that offer higher fitness returns (Waddington 1983; Thomas 2003; Newstrom \& Robertson 2005). While these visitation records demonstrate moth-plant interactions, 
further investigation into the nature of these associations is required before claims of moth pollination can be made. A strong correlation exists between the number of moth scales and the number of pollen grains deposited on stigmas (Weller et al. 2017). Documentation of such 'trace' evidence is a straightforward and valuable technique for determining the potential pollination effectiveness of flower feeding moths (e.g. Nilsson \& Rabakonandrianina 1988), particularly given the difficulties with observing floral visitors at night.

The presence of pollen on moth bodies is the most conclusive evidence available in support of moth pollination in New Zealand, yet it has been used only once compared with 187 mentions in the global literature. The singular New Zealand case was reported by Merrett et al. (2002), who removed Alseuosmia pollen, but no other pollen types, from the base of the proboscis of a Epyaxa rosearia (Geometridae) moth captured while feeding on Alseuosmia flowers. While pollen on a single individual does not prove that this species behaves as a pollinator, it is still highly informative and should be treated as a justification for further investigation.

The second largest category cited as evidence for moth pollination in New Zealand was inference from floral features thought to be consistent with a moth pollination syndrome (Faegri \& van der Pijl 1979). This is concerning, as the use of floral syndromes as a predictor of pollinator effectiveness is controversial. Ollerton et al. (2009) compared the most frequently observed putative pollinators of 482 plant species with their scores in multivariate floral phenotype space, and found that primary pollinators were correctly predicted by the most similar floral syndrome for only about one third of species. However, a review by Rosas-Guerrero et al. (2014) of published studies found that flower visitors that matched the pollination syndromes assigned to 417 plant species based on presence/absence of key floral traits, were significantly more 'effective' pollinators (based on a range of evidence types from visitation to experimental seed production) than flower visitors that did not match the assigned syndrome. These and other studies highlight the importance of understanding the relevance of floral traits to flower visitors and the importance of distinguishing types of evidence of pollination.

\section{Moth families in the New Zealand pollination literature}

In the New Zealand moth pollination literature, the greatest range of evidence coincided with cases where the identity of the moth was unknown; difficulties associated with field identifications and the limited number of skilled taxonomists may help explain this lack of identification. In contrast, the global literature has many moth families with a range of supporting evidence, highlighting the lack of information regarding the role certain families play as pollinators in New Zealand.

Of the eight moth families identified as pollinators in $\mathrm{New}$ Zealand, Geometridae and Noctuidae have received the most attention, consistent with the global findings of MacGregor et al. (2014). Geometridae is the only family referenced by more than one evidence type, with the remaining seven families supported by visitation data alone. Geometridae feed on nectar as adults and, in New Zealand, include many brightly coloured day-flying species, particularly in the subfamily Larentiinae, perhaps accounting for its prevalence in observational records. Primack (1983) recorded more moth species and a greater diversity offlowers visited in montane New Zealand vegetation for the Geometrid subfamily Larentiinae, than for any other moth family or subfamily. In alpine herbfield, Bischoff (2008) identified two species in subfamily Larentiinae together carrying pollen from four plant species (Gaultheria nubicola: Ericaceae and Gentiana corymbifera: Gentianaceae on Dasyuris austrina; Wahlenbergia albomarginata: Campanulaceae and Veronica thomsonii: Plantaginaceae on Paranotoreas ferox), but just one species of Noctuidae (Aletia panda) carrying one type of pollen (G. nubicola). In contrast to Geometridae and Noctuidae, Crambidae and Oecophoridae received few mentions in the literature. Both of these families are abundant in New Zealand and deserve further investigation. Oecophoridae was identified as including potential pollinators in New Zealand based on observed nectar-feeding from Kunzea ericoides (sensu lato, Myrtaceae) by an endemic Gymnobathra sp. (Gardner-Gee et al. 2014). Oecophoridae species were not identified in the global literature as including potential pollinators. As this family is both species rich and widely distributed, further investigation into its relationship with plants may uncover previously undescribed interactions both in New Zealand and globally. An additional 10 moth families that had been identified as pollinators globally have not been investigated in New Zealand, so future studies that target moths in these families may also uncover further plant-moth associations.

\section{Plant families in New Zealand moth pollination literature}

Globally, 76 plant families are currently identified as containing moth pollinated species. Surprisingly 32 of these, while present in New Zealand, have not been mentioned in the New Zealand moth pollination literature. In particular, the Orchidaceae is most frequently mentioned in the global moth pollination literature, yet received no mentions in the New Zealand literature, despite being species rich (107 species) and widely distributed in New Zealand. Studies of moth pollination in Orchidaceae often involve hawkmoths (Sphingidae) and flowers with long nectar spurs (e.g. Johnson \& Raguso 2016). New Zealand has only two non-native Sphingid moths, and most New Zealand orchids have relatively small flowers lacking nectar spurs. However, Noctuidae, which is abundant in New Zealand, has also been recorded pollinating orchids globally (MacGregor et al. 2014), and the New Zealand orchid genera Earina and Winika have some floral features suggestive of moth pollination. The only pollination study of these genera (Lehnebach \& Robertson 2004) limited pollinator observations to daylight hours, so moth pollination cannot yet be ruled out for New Zealand Orchidaceae.

Species from 31 New Zealand plant families have been suggested as benefitting from moth pollination to some degree and eight of these families were not associated with moth pollination globally. Therefore, the way in which moths interact with plants in these families both in New Zealand and globally requires further examination. These results highlight how the role of moths as pollinators is largely unexplored both globally (Bawa 1990; Scoble 1992; MacGregor et al. 2014), and in New Zealand (Newstrom \& Robertson 2005; Merrett et al.2007), and emphasises the need to include moths (and other nocturnal pollinators) in future studies on pollination ecology, particularly for the plant families identified in this analysis.

\section{New Zealand knowledge of moth pollination in an Australasian context}

The comparison with Australia puts New Zealand's understanding of moth pollination in an Australasian context. The range of evidence found in Australian literature was more varied and stronger than that found for New Zealand. In addition, unpublished student theses may contain further 
information on the role of moths as pollinators in Australia (as occurred in New Zealand), but this was not examined. The Australian moth fauna is more than 10 times the size of the New Zealand moth fauna ( $>20$ 000, Zborowski \& Edwards 2007; c.f. $\geq 2000$, Patrick 2007), so the relative paucity of mentions in the Australian literature suggests that the importance of moths as pollinators in Australia is even less well understood than in New Zealand. It is clear from this study that further work into the role and effectiveness of moths as pollinators is required on both regional and global scales.

\section{Conclusions}

Our analysis highlights the lack of information relating to moth-plant interactions in New Zealand, particularly for the categories of conclusive evidence that are available globally. An assessment of the importance of moth pollination in New Zealand is currently not possible due to visitation being the main, and arguably only, evidence currently available, and the bulk of the supporting evidence arising from observations of floral visitation where the identity of the moth is unknown. New Zealand's rich moth fauna is chronically understudied and field identification can be difficult, even for an expert, but the results from our review strongly suggest more mutualistic interactions are waiting to be discovered. However, care should be taken when making assumptions that moths are acting as pollinators. Recent work has shown that pollen transfer is a valuable indicator of pollinator effectiveness (Wilson \& Thomson 1991; King et al. 2013). Though recording how moths deposit pollen on stigmas in natural settings has some logistical issues (Fenster et al. 2004; McGregor et al. 2014), documenting pollen loads on moth bodies, quantifying pollen transfer, and conducting pollinator exclusion experiments can be both simple and highly informative, and it is this type of research that is needed to determine the effectiveness of moths as pollinators in New Zealand.

\section{Acknowledgements}

We would like to thank The University of Otago, Botany Department and Ruakura Research Centre at The New Zealand Institute for Plant \& Food Research Limited for allowing the use of facilities to undertake this research. Dr Robert Hoare (Landcare Research) kindly provided moth taxonomic information. We would like to thank Rauhina K. Scott-Fyfe for providing the Te Reo Māori translation of the abstract. Te Reo Māori moth family names are based on research for the MBIE funded Ahi Pepe MothNet Unlocking Curious Minds project. This research was generously funded by the Miss E.L. Hellaby Indigenous Grassland Research Trust and The Royal Forest and Bird Protection Society, Dunedin Branch.

\section{References}

Althoff DM 2016. Specialization in the yucca-yucca moth obligate pollination mutualism: a role for antagonism? American Journal of Botany 103: 1803-1809.

Bawa KS 1990. Plant-pollinator interactions in tropical rain forests. Annual Review of Ecology and Systematics 21: 399-422.
Benning JW 2015. Odd for an Ericad: nocturnal pollination of Lyonia Iucida (Ericaceae). The American Midland Naturalist 174: 204-217.

Bischoff M 2008. Pollination ecology of the New Zealand alpine flora. PhD thesis, University of Heidelberg, Heidelberg, Germany. 151 p.

Bischoff M, Lord JM, Robertson AW, Dyer AG 2013. Hymenopteran pollinators as agents of selection on flower colour in the New Zealand alpine region: salient chromatic signals enhance flower discrimination. New Zealand Journal of Botany 51: 181-193.

Burrows CJ 1960. Studies in Pimelea, I. The breeding system. Transactions of the Royal Society of New Zealand 88: 29-45.

Campbell DR, Bischoff M, Lord JM, Robertson AW 2010. Flower color influences insect visitation in alpine New Zealand. Ecology 91: 2638-2649.

Darwin C 1862. On the various contrivances by which British and foreign orchids are fertilized by insects. London, Murray.

de Lange PJ, Rolfe JR 2010. New Zealand indigenous vascular plant checklist 2010. Wellington, New Zealand, New Zealand Plant Conservation Network. 125 p.

Dieringer G 1992. Pollinator effectiveness and seed set in populations of Agalinis strictifolia (Scrophulariaceae). American Journal of Botany 79: 1018-1023.

Faegri K, van der Pijl L 1979. The principles of pollination ecology. 3rd edn. Oxford, Pergamon Press. 244 p.

Fenster CB, Armbruster WS, Wilson P, Dudash MR, Thomson JD 2004. Pollination syndromes and floral specialization. Annual Review of Ecology, Evolution and Systematics 35: 375-403.

Gardner-Gee R, Dhami MK, Paulin KJ, Beggs JR 2014. Can alternative sugar sources buffer pollinators from nectar shortages? Environmental Entomology 43: 1514-1525.

Genini J, Morellato LPC, Guimarães PR, Olesen JM 2010. Cheaters in mutualism networks. Biology Letters 6: 494-497.

Godley EJ 1979. Flower biology in New Zealand. New Zealand Journal of Botany 17: 441-466.

Hegland ST, Dunne J, Nielsen A, Memmott J 2010. How to monitor ecological communities cost-efficiently: the example of plant-pollinator networks. Biological Conservation 143: 2092-2101.

Heine EM 1937. Observations on the pollination of New Zealand flowering plants. Transactions of the Royal Society of New Zealand 67: 133-148.

Johnson SD, Raguso RA 2016. The long-tongued hawkmoth pollinator niche for native and invasive plants in Africa. Annals of Botany 117: 25-36.

Johnson SD, Steiner KE 2000. Generalization versus specialization in plant pollination systems. Trends in Ecology \& Evolution 15: 140-143.

Keighery GJ 1996. Phytogeography, biology and conservation of Western Australian Epacridaceae. Annals of Botany 77: 347-355.

King C, Ballantyne G, Willmer PG 2013. Why flower visitation is a poor proxy for pollination: measuring single-visit pollen deposition, with implications for pollination networks and conservation. Methods in Ecology and Evolution 4: 811-818.

Lehnebach CA, Robertson AW 2004. Pollination ecology of four epiphytic orchids of New Zealand. Annals of Botany 93: 773-781. 
Lloyd DG 1985. Progress in understanding the natural history of New Zealand plants. New Zealand Journal of Botany 23: 707-722.

MacGregor CJ, Pocock MJ, Fox R, Evans DM2014. Pollination by nocturnal Lepidoptera, and the effects of night pollution: a review. Ecological Entomology 40: 187-198.

Merrett MF, Clarkson BD, Bathgate JL 2002. Ecology and conservation of Alseuosmia quercifolia (Alseuosmiaceae) in the Waikato region, New Zealand. New Zealand Journal of Botany 40: 49-63.

Merrett MF, Robertson AW, Peterson PG 2007. Pollination performance and vulnerability to pollination breakdown of sixteen native shrub species from New Zealand. New Zealand Journal of Botany 45: 579-591.

Miller CM, Barratt BIP, Dickinson KJM, Lord JM In review. Asymmetry and compartmentalisation among native and non-native species in an alpine-montane pollination network. Perspectives in Plant Ecology, Evolution and Systematics.

Morris WF, Vazquez DP, Chacoff NP 2010. Benefit and cost curves for typical pollination mutualisms. Ecology 91: 1276-1285.

Newstrom L, Robertson A 2005. Progress in understanding pollination systems in New Zealand. New Zealand Journal of Botany 43: 1-59.

Nilsson LA, Rabakonandrianina E 1988. Hawk-moth scale analysis and pollination specialization in the epilithic Malagasy endemic Aerangis ellisii (Reichenb. fil.) Schltr. (Orchidaceae). Botanical Journal of the Linnean Society 97: 49-61.

Ollerton J, Alarcon R, Waser NM, Price MV, Watts S, Cranmer L, Hingston A, Peter CI, Rotenberry J 2009. A global test of the pollination syndrome hypothesis. Annals of Botany 103: $1471-1480$.

Patrick B 2007. 'Butterflies and moths - New Zealand's butterflies and moths'. Te Ara - the Encyclopedia of New Zealand. www.TeAra.govt.nz/en/butterflies-and-moths/ page-1 (accessed 8 June 2017).

Pattemore DE, Anderson SH 2013. Severe pollen limitation in populations of the New Zealand shrub Alseuosmia macrophylla (Alseuosmiaceae) can be attributed to the loss of pollinating bird species. Austral Ecology 38: 95-102.

Pattemore DE, Wilcove DS 2012. Invasive rats and recent colonist birds partially compensate for the loss of endemic New Zealand pollinators. Proceedings of the Royal Society 279: $1597-1605$.

Popic TJ, Wardle GM, Davila YC 2013. Flower-visitor networks only partially predict the function of pollen transport by bees. Austral Ecology 38: 76-86.

Primack RB 1978. Variability in New Zealand montane and alpine pollinator assemblages. New Zealand Journal of Ecology 1: 66-73.

Primack RB 1983. Insect pollination in the New Zealand mountain flora. New Zealand Journal of Botany 21: 317-333.

Proctor M, Yeo P, Lack A 1996. The natural history of pollination. London, Harper Collins. 479 p.

Robertson AW 1989. Evolution and pollination of New Zealand Myosotis (Boraginaceae). PhD thesis, University of Canterbury, Christchurch, New Zealand. 160 p.

Rodger JG, van Kleunen M, Johnson SD 2010. Does specialized pollination impede plant invasions? International Journal of Plant Sciences 171: 382-391.

Rosas-Guerrero V, Aguilar R, Marten-Rodriguez S, Ashworth
L, Lopezaraiza-Mikel M, Bastida JM, Quesada M 2014. A quantitative review of pollination syndromes: do floral traits predict effective pollinators? Ecology Letters 17: 388-400.

Scoble MJ 1992. The Lepidoptera: form, function and diversity. New York, Oxford University Press. 420 p.

Spears EE 1983. A direct measure of pollinator effectiveness. Oecologia 57: 196-199.

Stevens PF 2001. Angiosperm Phylogeny Website. Version 12, July 2012. www.mobot.org/MOBOT/research/APweb (accessed 20 August 2015).

Thomas JD 2003. When is it mutualism? The American Naturalist 162: S1-S9.

Thomson GM 1881. On the fertilization of flowering plants. Transactions and Proceedings of the New Zealand Institute 13: 241-291.

Thomson GM 1928. The pollination of New Zealand flowers by birds and insects. Transactions and Proceedings of the New Zealand Institute 57: 106-125.

Van Nieukerken EJ, Kaila L, Kitching IJ, Kristensen NP, Lees DC, Minet J, Mitter C, Mutanen M, Regier JC, Simonsen TJ, Wahlberg N, Yen SH, Zahiri R, Adamski D, Baixeras J, Bartsch D, Bengtsson BA, Brown JW, Bucheli SR, Davis DR, De Prins J, De Prins W, Epstein ME, Gentili-Poole P, Gielis C, Hättenschwiler P, Hausmann A, Holloway JD, Kallies A, Karsholt O, Kawahara AY, Koster SJC, Kozlov MV, Lafontaine JD, Lamas G, Landry JF, Lee S, Nuss M, Park KT, Penz C, Rota J, Schintlmeister A, Schmidt BC, Sohn JC, Solis MA, Tarmann GM, Warren AD, Weller S, Yakovlev RV, Zolotuhin VV, Zwick A 2011. Order Lepidoptera Linnaeus, 1758. In: Zhang ZQ ed. Animal biodiversity: an outline of higher-level classification and survey of taxonomic richness. Zootaxa 3148. Auckland, New Zealand, Magnolia Press. Pp. 212-221.

van Welzen PC, Pruesapan K, Telford IRH, Bruhl JJ 2015. Historical biogeography of Breynia (Phyllanthaceae): what caused speciation? Journal of Biogeography 42: 1493-1502.

Waddington KD 1983. Foraging behaviour of pollinators. Chapter 9. In: Real L ed. Pollination biology. Orlando, Academic Press Inc. Pp. 213-239.

Weller SG, Sakai AK, Campbell DR, Powers JM, Pena SR, Keir MJ, Loomis AK, Heintzman SM, Weisenberger L 2017. An enigmatic Hawaiian moth is a missing link in the adaptive radiation of Schiedea. New Phytologist 213: $1533-1542$.

Wilson P, Thomson JD 1991. Heterogeneity among floral visitors leads to discordance between removal and deposition of pollen. Ecology 72: 1503-1507.

Yoder JB, Smith CI, Pellmyr O 2010. How to become a yucca moth: minimal trait evolution needed to establish the obligate pollination mutualism. Biological Journal of the Linnean Society 100: 847-855.

Zborowski P, Edwards T 2007. A guide to Australian moths. CSIRO Publishing, Canberra. 224 p.

Editorial board member: Jamie Wood

Received 27 July 2017; accepted 15 November 2017 